\begin{tabular}{|c|c|c|}
\hline L.3 & $\begin{array}{c}\text { European Association for the } \\
\text { Development of Renewable Energies, } \\
\text { Environment }\end{array}$ & $\begin{array}{c}\text { International Conference on Renewable Energies } \\
\text { and Power Quality (ICREPQ'12) }\end{array}$ \\
$\begin{array}{c}\text { and Power Quality (EA4EPQ) } \\
\text { Santiago de Compostela (Spain), 28th to 30th March, } 2012\end{array}$ \\
\hline
\end{tabular}

\title{
Power Quality impact of a small wind energy conversion system connected to the LV grid
}

\author{
A. Arroyo, M. Mañana, L.M. Muñiz, R. Martínez and C. Capellan \\ Department of Electrical Engineering \\ E.T.S.I.I.T. University of Cantabria \\ Avda. Los Castros s/n \\ 39005 Santander, Cantabria \\ Spain \\ Phone: +34942201378 Fax: +34942201385 Email: mananam@unican.es
}

\begin{abstract}
This research work is devoted to the study of the Power Quality (PQ) impact of small wind energy conversion systems (SWECS) connected to the low voltage grid. A common coupling point (CCP) has been monitored using a PQ meter that fulfils the standard IEC 61000-4-30 class A. The PQ survey has been conducted with and without the SWECS and the results were compared with the limits defined by the standard EN 50160 .
\end{abstract}

\section{INTRODUCTION}

Small Wind Energy Conversion Systems (SWECS) can be considered a hot topic. The increase in the individual power of the wind turbines and the aggregation of sets of turbines in wind farms increase their impact on the power quality level of the distribution network. The main reason is due to the variability of the injected wind power that affects some parameters of the voltage quality. The standard EN 50.160 [1] defines the voltage characteristics of the electricity supplied by public electricity networks. This document established the disturbance limits for distribution networks with voltages up to $150 \mathrm{kV}$. During the last years PQ experts have been focusing on the problems produced by wind farms of significant power (more than $20 \mathrm{MW}$ ) due to their large impact on the distribution networks [2-8]. Since the beginning of the wind industry, manufacturers have been extended the rated capacity of their machines from some tens of $\mathrm{kW}$ to todays MW turbines. The state of the art technology can provide commercial-grade wind generators for offshore applications with rated power of more than $6 \mathrm{MW}$. The standard IEC 61400-21 [9] provides a methodology suitable for determining the PQ characteristics of wind turbines considering not only the specific turbine technology but also the common coupling point where the turbine or set of turbines will be connected.

\section{EXPERIMENTAL FACILITY}

The study has been conducted on a LV distribution network sited on an industrial area. Fig. 1 shows a 3.5 $\mathrm{kW}$ small-wind generator (SWG) analyzed in our study.

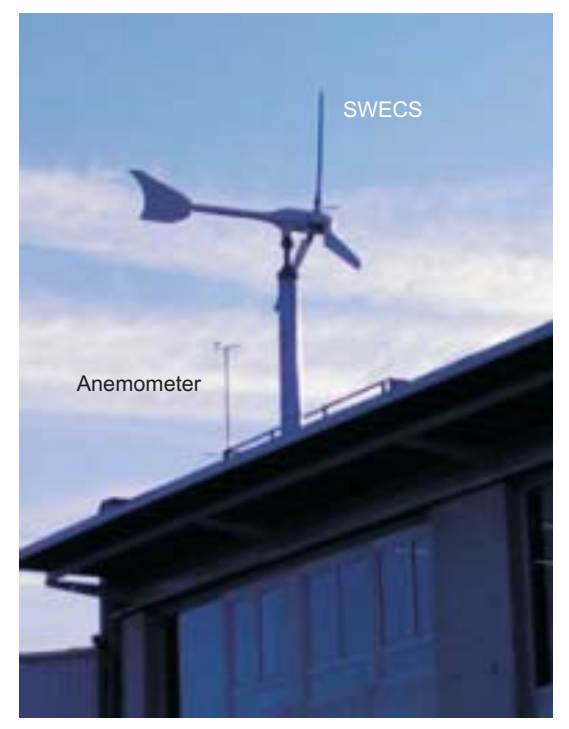

Figure 1. Small-wind generator of $3.5 \mathrm{~kW}$ analyzed. 
The system under study that is shown in Fig. 1 includes the SWG, the annemometer and the PQ meter. Fig. 2 shows the architecture of the radial distribution network where the SWECS is integrated.

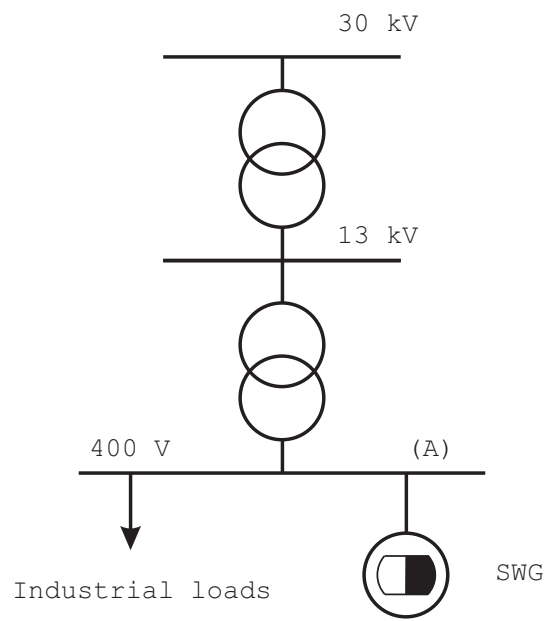

Figure 2. LV distribution network with the SWECS under study,

Fig. 3 shows the block diagram of the SWECS, the wind speed datalogger and the PQ instrumentation.

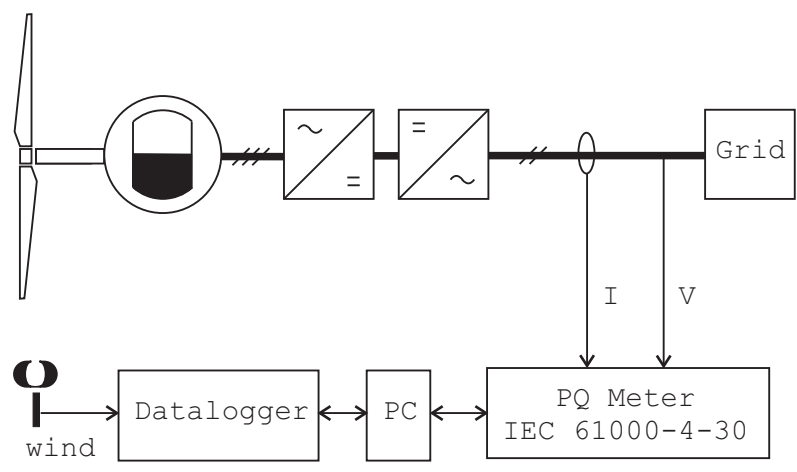

Figure 3. Block diagram of the SWECS analyzed with the PQ instrumentation and wind datalogger.

The tests have been conducted during different periods of time and under different weather conditions.

\section{PQ REQUIREMENTS}

The IEEE standard 1159 [10] provides a useful guide for PQ monitoring. The document covers the measurement of conducted disturbances in low-frequency. The european EN standard 50160 [1] defines the voltage characteristics of electricity supplied by public distribution systems. This document defines the threshold levels and the period of aggregation of measurements. From an instrumentation point of view, flicker parameter $P_{s t}$ has to be measured and computed according the IEC standard 61000-4-15 [11]. In addition, harmonic distortion has to be evaluated according the IEC standard 61000-4-7 [12].

\section{Results}

The system shown in Fig. 3 has been analyzed in different wind conditions. Fig. 4 shows a comparison of wind speed, active power, flicker and harmonic distortion during one of the studied period.
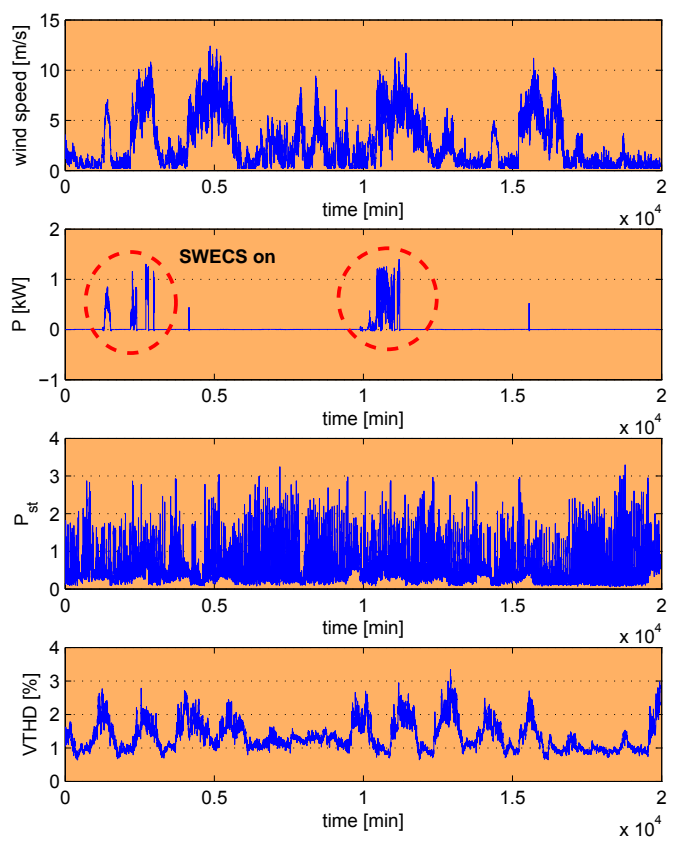

Figure 4. Historical evolution of wind speed, active power produced by the SWECS, $P_{s t}$ and $V T H D$.

Fig. 5 shows the probability density function (pdf) of wind speed during the period of analysis. The measured data has been fit to a theoretical Weibull distribution [13], [14].

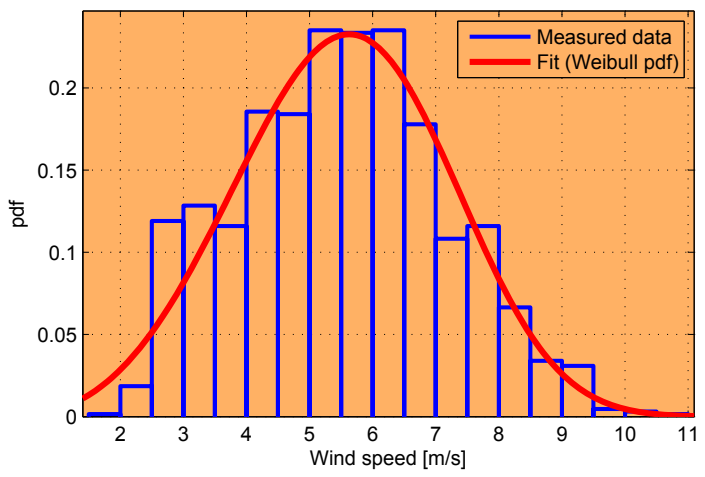

Figure 5. Statistical distribution of wind speed.

Fig. 6 shows the active power $P$ vs wind speed $v$ during the PQ survey. The wind speed during the test was in the range that goes from 1.8 to $10.8 \mathrm{~m} / \mathrm{s}$ with a mean value of $5.5 \mathrm{~m} / \mathrm{s}$. 


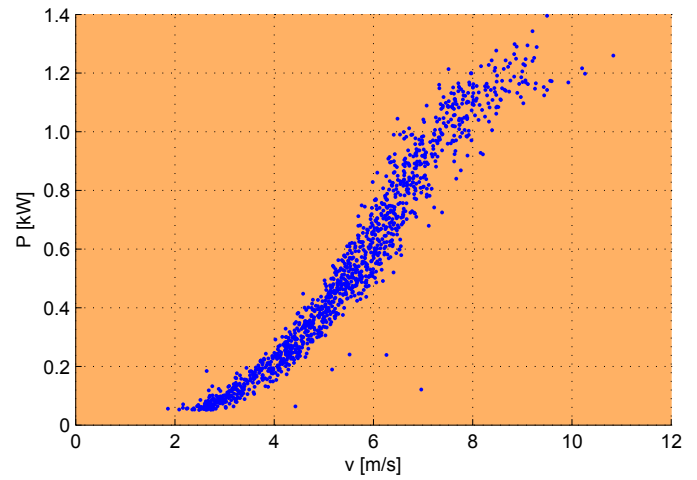

Figure 6. Experimental power curve $P$ vs $v$ computed during the $\mathrm{PQ}$ survey.

Fig. 7 shows the correlation between the measured flicker $P_{s t}$ and wind speed when the SWECS is not running. Fig. 7 shows that $P_{s t}$ is independent of the wind speed.

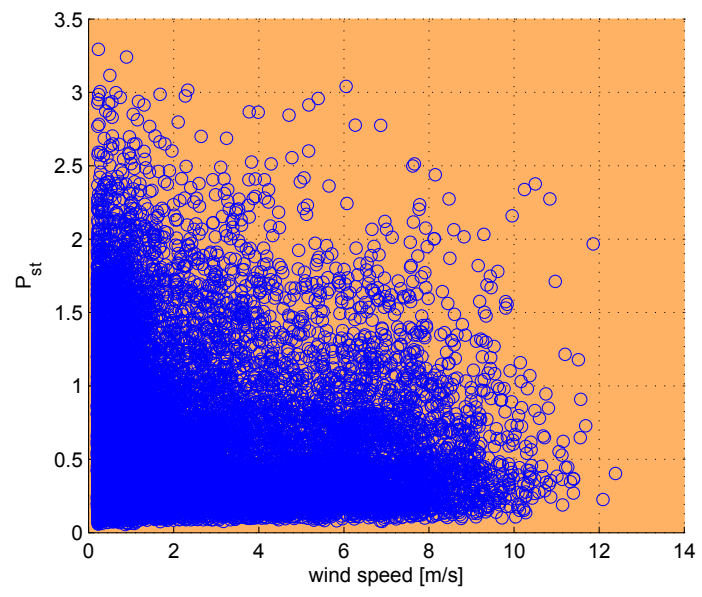

Figure 7. Flicker $P_{s t}$ vs $v$ measured during the PQ survey. The SWECS is not running.

Fig. 8 shows the correlation between the measured flicker $P_{s t}$ and wind speed when the SWECS is connected to the grid. From a statistical point of view it is possible to define a proportional relation between the flicker $P_{s t}$ and the wind speed $v$.

$$
P_{s t}(v)=0.29+0.073 v
$$

The constant value in Eq. 1 defines the mean value of the flicker and it is independent of the SWECS. The proportional constant 0.073 depends on the ratio between the power of the SWECS and the short-circuit power $S_{c c}$ at the common coupling point (point (A) in Fig. 2), the active and reactive power connected thereto and the line impedance.

Fig. 9 shows the correlation between the voltage distortion $V T H D$ and the wind speed when the SWECS is

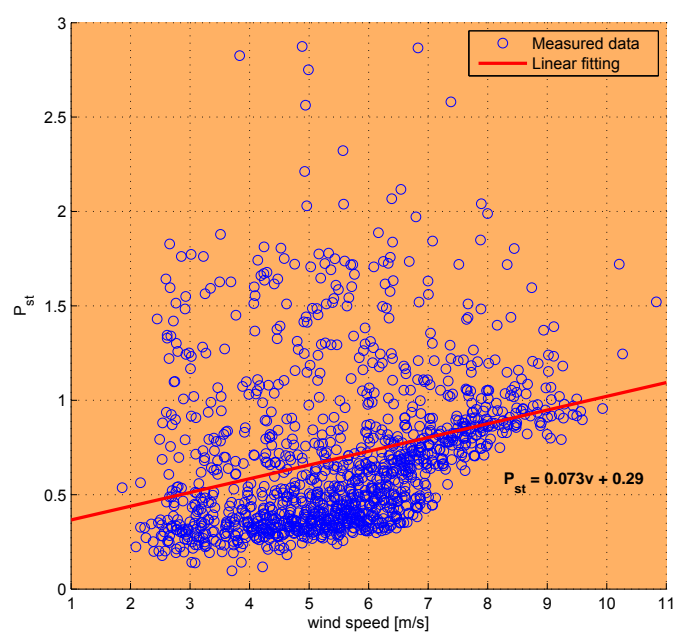

Figure 8. Flicker $P_{s t}$ vs $v$ measured during the PQ survey and computed linear fitting. The SWECS is running.

not running. As in the case shown in Fig. 7 the voltage distortion is independent from the wind speed.

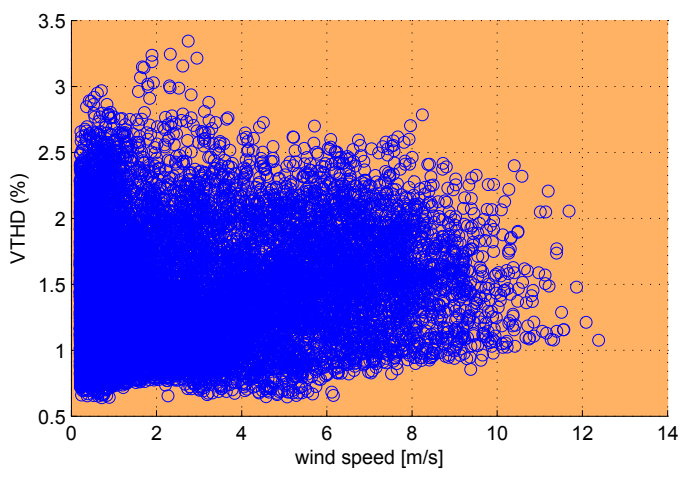

Figure 9. Distortion $V T H D$ vs $v$ measured during the PQ survey. The SWECS is not running.

Fig. 10 shows the correlation between the voltage distortion $V T H D$ and the wind speed when the SWECS is running.

Eq. 2 shows that there is a small proportional relation between the voltage distortion at the common coupling point and the wind speed.

$$
T H D V(v)=1.1+0.047 v
$$

\section{CONCLUSiOnS}

This research work analyzes the power quality impact produced by the integration of a Small Wind Energy Conversion System in a Low-Voltage distribution network. In spite of the fact that the small-wind generator has a reduced nominal power of $3.5 \mathrm{~kW}$, it is possible to 


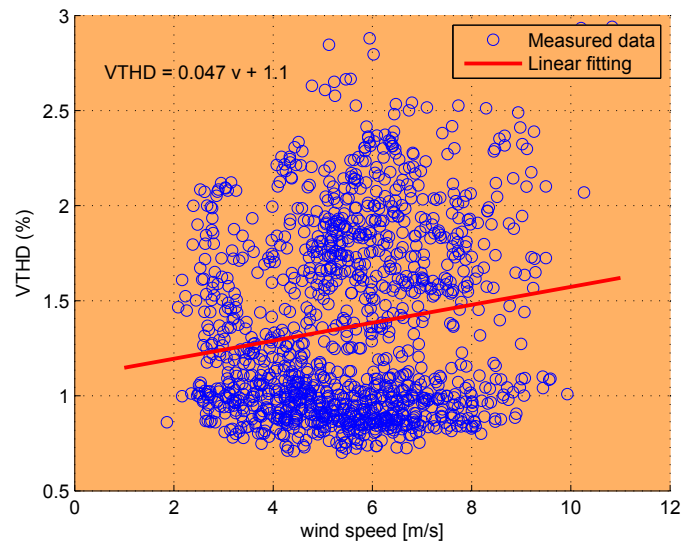

Figure 10. Distortion $V T H D$ vs $v$ measured during the PQ survey and computed linear fitting. The SWECS is running.

detect small increments in the values of the flicker $P_{s t}$ and voltage distortion $V T H D$.

\section{ACKNOWLEDGEMENT}

This research work was supported by the Spanish Goverment under grant number ENE2007-68032-C04-04, Cantabria Goverment under the R+D 2009 initiative and SONKYO Group.

\section{References}

[1] EN-50160, Voltage characteristics of electricity by public electricity networks, 2011.

[2] S. Heier, Grid Integration of Wind Energy Conversion Systems. England: John Wiley and Sons Ltd., 2006.

[3] R. Fadaeinedjad, M. Moallem, G. Moschopoulos, and S. Bassan, "Flicker contribution of a wind power plant with single and multiple turbine representations," in Electrical Power Conference, 2007. EPC 2007. IEEE Canada, oct. 2007, pp. $74-79$.

[4] R. Fadaeinedjad, G. Moschopoulos, and M. Moallem, "Flicker contribution of a wind turbine in a stand-alone wind diesel system," in Electrical and Computer Engineering, 2008. CCECE 2008. Canadian Conference on, may 2008, pp. $000233-000238$.

[5] T. Sun, Z. Chen, and F. Blaabjerg, "Flicker study on variable speed wind turbines with doubly fed induction generators," Energy Conversion, IEEE Transactions on, vol. 20, no. 4, pp. 896 - 905, dec. 2005.

[6] A. de Moura and A. de Moura, "Analysis of injected apparent power and flicker in a distribution network after wind power plant connection," Renewable Power Generation, IET, vol. 2, no. 2, pp. $113-122$, june 2008

[7] Z. Saad-Saoud and N. Jenkins, "Models for predicting flicker induced by large wind turbines," Energy Conversion, IEEE Transactions on, vol. 14, no. 3, pp. $743-748$, sep 1999.

[8] C. Wei, M. Han, and W. Yan, "Voltage fluctuation and flicker assessment of a weak system integrated wind farm," in Power and Energy Society General Meeting, 2011 IEEE, july 2011, pp. $1-5$.

[9] IEC-61400-21, Wind turbines - Part 21: Measurement and assessment of power quality characteristics of grid connected wind turbines, 2008.

[10] IEEE-Std-1159-2009, IEEE Recommended Practice for Monitoring Electric Power Quality (Revision of IEEE Std 1159-1995), 2009.

[11] IEC-61000-4-15, Electromagnetic Compatibility (EMC), Part 415: Testing and measurement techniques. Flickermeter, Functional and design specifications, 2004.
[12] IEC-61000-4-7, Electromagnetic Compatibility (EMC), Part 4-7: Testing and measurement techniques. General Guide on harmonics and interharmonics measurements and instrumentation, for power supply systems and equipment connected thereto., 2004.

[13] M. Sathyajith, "Wind energy. fundamentals, resource analysis and economics," in Springer, 2006, pp. 1-167.

[14] N. Milivojevic, I. Stamenkovic, and N. Schofield, "Power and energy analysis of commercial small wind turbine systems," in Industrial Technology (ICIT), 2010 IEEE International Conference on, march 2010, pp. $1739-1744$. 